\title{
Research on English Online Learning Community based on Social Network Site (SNS)
}

\author{
GUO Leilei, a , LIU Mengying ${ }^{2}$, XIAO Hong ${ }^{3}$ \\ ${ }^{1,2}$ Sci-tech School of Gannan Normal College, Ganzhou 341000,China \\ ${ }^{3}$ Ganzhou investigation team of National statistics bureaus, Ganzhou 341000,China \\ agrape_1118@163.com
}

Keywords: English Learning; Online Community; Social Network Site;

\begin{abstract}
With the increasing development of Internet technology and the concept of education and the increasing integration of information technology, online learning based on the SNS community model appear constantly. On this issue, the SNS gene can be used to design the learner's emotional communication and create a learning atmosphere and the teachers, classmates, and partners. Well-known, the positive energy will lead people to overcome difficulties and setbacks. If more about the factors of human emotions can be considered in design and development of the network course, learners are concerned about, help, encourage, happy, hoping to communicate with others, the learning process is likely to become more attractive and interesting. The systematic analysis proves the feasibility of the SNS based online learning platform. In the future, we plan to use Java to develop the platform to make it more applicable.
\end{abstract}

\section{Introduction}

Online learning and traditional face-to-face teaching is the fundamental difference between a series of tracking problem of different information carrier and transmission method, such as the difference of teaching design, teaching, learners' emotional state, a way of communication, and so on. At present, the focus of the conflict both at home and abroad suffers from many complaints both designers and users of online learning platform. Whether it is an open class record model based on video on demand, or micro courses according to knowledge, or game mode of learning, learners' common sense too hard if continue to study learning motivation disappeared quickly in online learning, then it is easy to give up halfway. Online learning has few studies finally completed. Network education and traditional education, an important factor which causes the result is emotional difficulty of one online education not solved. In the traditional teaching, it is a process of a face to face with the teachers, classmates, and interesting communication. However, online learning, learners always facing the cold machine interaction is less, most of the time, the learners learning courses. No teacher or a classmate remind learners when they take a nap, no one encourage them when they do well, only one person in the study. With the passage of time, learning enthusiasm fade, learners may give up online course of a day. On this issue, the SNS gene can be used to design the learner's emotional communication and create a learning atmosphere and the teachers, classmates, and partners. Well-known, the positive energy will lead people to overcome difficulties and setbacks. If more about the factors of human emotions can be considered in design and development of the network course, learners are concerned about, help, encourage, happy, hoping to communicate with others, the learning process is likely to become more attractive and interesting. The significance of SNS application gene in online learning is to create a virtual classroom learning and "realism", made the learning of the information dissemination process closer to real life.

Internet age is an open, sharing, and free era, which has brought massive learning resources, regretfully, so many learners participate in online learning, but very few of them finish the study eventually. After comparing the online education and traditional education, an important factor leading to this result is the emotional issue in online education has not been solved well. In the traditional teaching, it is a face-to-face process with teachers, classmates, and fun of communications. 
However, in online learning, what the learners always face is the cold machine with less interaction, and most of the time, the learners study the courses alone. No teachers or classmates remind the learners when they nap, and nobody encourage them when they do well, just one person in the study.

To deal with the proposed issues above, we conduct research on English online learning community based on social network site in this paper. The general structure of the proposed model is shown in the figure 1 . The detailed discussion is conducted in the following sections.

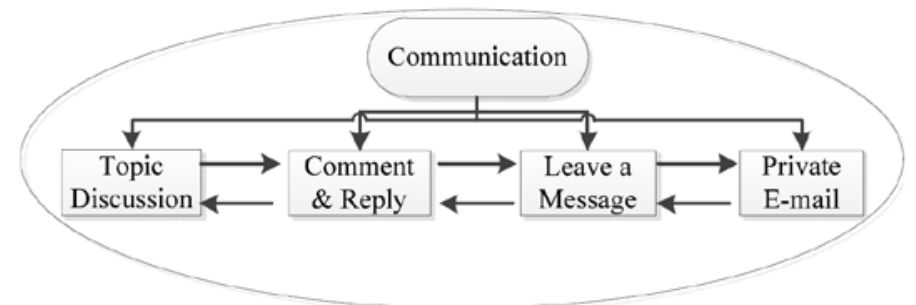

Figure 1. The General Structure of Online Learning Process

\section{The Community Design and Description}

The MOOC Organizing Principles. MOOC curriculum organization form is mainly affected by the association of socialism, associated doctrine: the main point of the pipe is more important than the content in the pipeline, argues that created by people and content enhanced personal learning network, the node of technologies such as claims certain knowledge flow of the processing and interpretation functions to study the nodes on the network. As the social public oriented free open online courses, emphasis on interpersonal channels of knowledge sharing and sharing mode of MOOC courses basically has the following principle. The first principle: gather. MOOC the core and key points of course is to provide a different places in the starting point of the development of mass learning content online, these learning content is then gathered together, as a kind of presentation or a web page, so that participants can access on a regular basis. This is the important difference between it with the traditional curriculum. In traditional course, learning content is prepared ahead of time by the teacher. In the MOOC course, most of the content is dynamic collection. Courses for distribution throughout the Internet mass content provides a collection points, these content via the web or course communication form of polymerization for users, learning is endless, learners may not read all of the content, they should choose according to their interests to learn. The second principle: restructuring. Learners in the learning process will be the contents of the curriculum and curriculum materials are mixed, mutual connection and mutual reference and contact, combine the learners' own resources and curriculum resources, reorganize together for study use. By writing blog, for example, social bookmarking record and share new resources, participate in the BBS discussion, brief comment, etc. The third principle: to adopt. According to the learner's own goal tailored to adapt to each learner and participants, switch to aggregate the curriculum resources of mixture and resources for learning. Course aim is not to let learners repeat existing content, but encourage them on the basis of the different. The learners can be based on the knowledge courses, according to their own understanding and ideas in the new learning content. The fourth principle: to share. In accordance with the specific purpose, learners should be actively with other learners of the course and course of all people to share their ideas and contents of the creation, hybrid, or switch to, cause more response and comments. The content of the share can be a new resources, new ideas and new insights. These valuable parts of the content will be course coordinator aggregated into the course. These principles summarized the MOOC course of produce, share and create knowledge such as the process of growth and spread. MOOC besides depends on the willing to contributions to the development of creators and share of course, also cannot leave the knowledge sharing platform or environment, communication medium, platform, and health is MOOC transmission of the ecological environment is very important, also is the key to the sustainable development of the MOOC factors. 
The Learning Motivation Influence Analysis of Network Learning. In order to study the psychological factors affecting the effects of online learning, the author and some organized a survey online learning website, randomly chose 200 students in 50000 registered students as samples, by telephone survey 200 target learners and analysis of site data. In the survey found that the comprehensive course completion total of course completion/total number of choosing courses, and course comprehensive completion rate was only $0.62 \%$. We also calculate if they have learnt the course, that is assuming that when completed research, as long as they see all the time, a course completion rate is $4.53 \%$, while the computation than the first one way, still showed that many learners did not complete the course. Basically, most students study in the network, the lack of sharing with others. Many services such as network courses provide message boards and email communication, such as online discussion, although, according to data from only a few students to participate in the communication and discussion, even if to participate in, most of whom were seeking answers to questions. Making it impossible to achieve the goal of collaborative learning, can't let individual learners to adapt to the circle of research activities, learners make it difficult to keep learning, and lack of necessary communication and encouragement. And then give up study inevitable. Therefore, the study time is positively related to give up learning factors. The figure 2 shows the statistical result for the test.

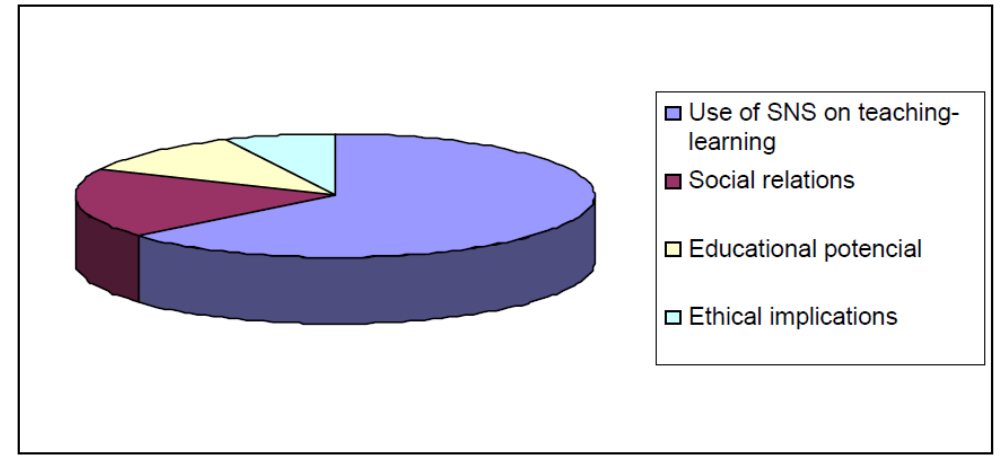

Figure 2. The Statistical Result for the Test

The Systematic Description. In the process of developing online courses, the designer should pay more attention to the role of E-portfolio, do the data mining based on learning records, focus on the evaluation of the learning process, and provide objective and quantitative formative evaluation reports for the learners. Meanwhile, the learning progress could be tracked by setting the end time and calculating the required amount of daily study and review automatically. The learners could see the learning progress in the user interface and receive a learning reminder through e-mail, push messages and other ways. The figure 3 shows the systematic description.

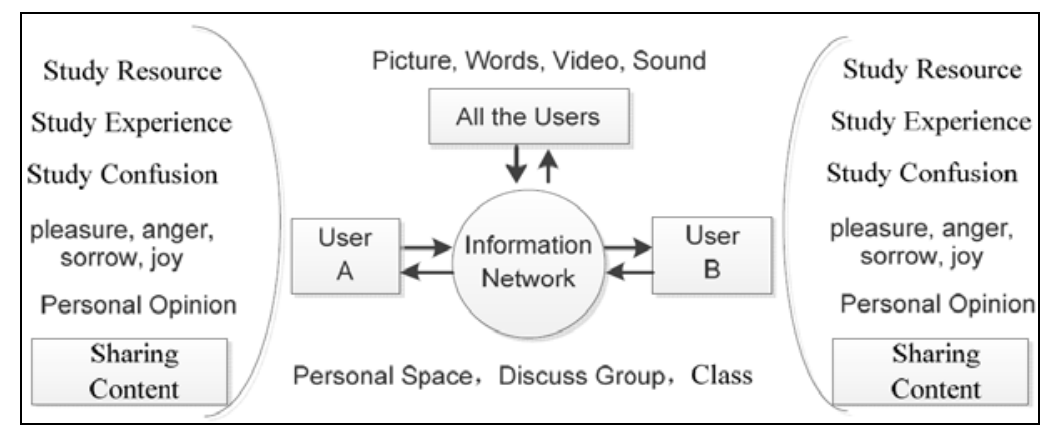

Figure 3. The Systematic Description

When the learners login to the online courses for the first time, the system will show all the courses and require the learners to select the course chapter(s) they would like to study. After this, the learners may need to set a schedule that how long they plan to complete the learning of the whole course or one chapter. Then, the system will calculate the amount of daily learning based on the current time and will also record the daily progress automatically. If the learners do not complete the required learning, or they stop the learning for many days, the system will inform them of the learning progress by e-mail or push messages, and remind them to continue to learn the course. Cloud learning has 
universal accessibility, collaborative interaction, stability, economy, and individual characteristics, learning concept spread at the same time, the clouds cloud also gradually appear the concept of learning environment, it is generally believed, based on cloud computing technology to create an open learning environment, namely the cloud learning environment, emphasize the learners as the center, emphasizes the learners should play the role of cognitive subject, is the place that support and promote learning, learners can free exploration and autonomous learning, is to provide learners with the place of all forms of learning support and service. Cloud learning environment inherited an important part of the learning environment of the four, respectively is situation, resources, tools and support, at the same time, the cloud learning environment is a kind of digital learning ecological system, a unified deployment, strong extensibility, high resource utilization, good security, flexible operation, dynamic allocation calculation, recycling and excellent cost-effective. Construction of cloud learning environment based on cloud computing is the development direction of distance education, learning to solve both the web conditions during the age of the cloud in the circulation, the unstructured knowledge learners focus too scattered, also stressed that the height of the loose aggregation, a high degree of knowledge sharing, efficient information flow, and a high degree of initiative should and multidimensional. In summary, the proposed system is robust and necessary.

\section{Conclusion and Summary}

With the increasing development of Internet technology and the concept of education and the increasing integration of information technology, online learning based on the SNS community model appear constantly. At present, the focus of the conflict both at home and abroad suffers from many complaints both designers and users of online learning platform. Whether it is an open class record model based on video on demand, or micro courses according to knowledge, or game mode of learning, learners' common sense too hard if continue to study learning motivation disappeared quickly in online learning, then it is easy to give up halfway. Online learning has few studies finally completed. Network education and traditional education, an important factor which causes the result is emotional difficulty of one online education not solved. In this paper, we conduct research on English online learning community based on social network site in this paper. The analysis proves the feasibility of our ideal. In the future, we have scheduled to apply the proposed methodology to more conditions to test the robustness of our system.

\section{References}

[1] Yang L, Ouyang F. Building Online Learning Community for Higher Education[J]. ICCIA-12, 2014.

[2] Cheung T C, Cheung H, Mark K. A Study of the Impact of a Crowd Wisdom Online Learning Community Platform on Student Learning[J]. "A STUDY OF THE IMPACT OF A CROWD WISDOM ONLINE LEARNING COMMUNITY PLA" by Terence Chun-Ho CHEUNG, Hokling CHEUNG et al., 2014.

[3] Tang E, Lam C. Building an effective online learning community (OLC) in blog-based teaching portfolios[J]. The Internet and Higher Education, 2014, 20(1):79-85.

[4] Bergstresser E, Bergstresser E. Teacher and learner perceptions of community in online learning environments[J]. Dissertations \& Theses - Gradworks, 2014.

[5] Johnson H, Mejia M C. Online learning and student outcomes in California's community colleges[J]. Public Policy Institute of California, 2014.

[6] Learning J O C A, Jun V N P. Guidelines for Facilitating the Development of Learning Communities in Online Courses[J]. Journal of Computer Assisted Learning, 2014, 30(3):220-232. 
[7] So C K K K F. Creating a Virtual Learning Community to Engage International Students[J]. Journal of Hospitality \& Tourism Education, 2014, 26(3):136-146.

[8] Shea P, Bidjerano T. Does online learning impede degree completion? A national study of community college students[J]. Computers \& Education, 2014, 75(2):103-111.

[9] Hou H. What makes an online community of practice work? A situated study of Chinese student teachers' perceptions of online professional learning[J]. Teaching and Teacher Education, 2015:6-16.

[10]Linton J N, GREENSBORO T U O N C A. A qualitative case study of an electronic learning community as a community of practice for new and veteran online teachers[J]. Dissertations \& Theses - Gradworks, 2014. 